\title{
Peningkatan Sistem Pengelolaan E-Journal Berbasis Open Journal System (OJS) 2.4.8 ke Versi 3.1.0.1
}

\author{
Upgrade system e-journal management based open \\ journal system (OJS) 2.4.8 to version 3.1.0.1
}

\author{
Indri Handayani ${ }^{1}$, Erick Febriyanto ${ }^{2}$, Muhammad Shofwatullah ${ }^{3}$ \\ ${ }^{1}$ Dosen STMIK Raharja Jurusan Sistem Informasi Informasi, ${ }^{2}$ Dosen STMIK Raharja Jurusan \\ Sistem Informasi, ${ }^{3}$ Mahasiswa STMIK Raharja Jurusan Sistem Informasi \\ indri@raharja.info, ${ }^{2}$ erick@raharja.info, ${ }^{3}$ shofwatullah@raharja.info
}

\begin{abstract}
Abstrak
Jurnal merupakan sebuah karya tulis ilmiah yang berisi informasi dan ilmu pengetahuan hasil dari suatu penelitian. Pada salah satu perguruan tinggi yang berlokasi di wilayah Kota Tangerang yang menjadi objek penelitian, sudah menerapkan ePublishing system berbasis Open Journal Systems (OJS) Versi 2.4.8. Namun, pada OJS versi 2.4.8 yang digunakan saat ini, belum memiliki fitur-fitur yang dapat mempercepat alur proses pengelolaan dan penerbitan jurnal yang diarahkan oleh OJS, karena semakin banyak artikel yang masuk, serta memiliki tampilan yang cenderung kaku dan tidak ada perbedaan antara tampilan halaman depan (front-end) dengan tampilan halaman belakang (back-end). Maka diperlukan sebuah sistem yang mampu dioperasikan lebih efektif dan efisien serta memiliki fitur yang dapat mempercepat alur proses pengelolaan dan penerbitan jurnal sehingga dapat menghemat waktu dan mempercepat proses penerbitan, dan memiliki tampilan yang ramah pengguna (userfriendly) sehingga dapat memudahkan pengguna ketika berinteraksi dengan sistem. Metode penelitian yang digunakan dalam penelitian ini antara lain metode analisis permasalahan, metode analisis kebutuhan proses peningkatan versi sistem, dan metode pengembangan perangkat lunak menggunakan metode Waterfall. Setelah melakukan peningkatan versi ePublishing system berbasis Open Journal System (OJS) Versi 2.4.8 menjadi Versi 3.1.0.1, proses pengelolaan menjadi lebih flexible dan efisien, serta memiliki tampilan yang lebih menarik dan dapat dikustomisasi.
\end{abstract}

Kata Kunci-Peningkatan Sistem, Open Journal System (OJS), Waterfall.

\begin{abstract}
Journal is a scientific paper that contains information and science the results of a study. At one of the universities located in the Tangerang City area which is the object of research, it has implemented an ePublishing system based on Open Journal Systems (OJS) Version 2.4.8. However, in OJS version 2.4 .8 currently in use, it does not yet have features that can speed up the flow of the journal management and publishing process directed by OJS, because more and more articles are entered, and have a display that tends to be rigid and there is no difference between front-end display with back-end display. So we need a system that is able to operate more effectively and efficiently and has features that can accelerate the flow of the management and publishing process so that it can save time and speed up the publishing process, and have a user-friendly appearance so that users can easily interact with system. The research method used in this study include the problem analysis method, the method of analyzing the needs of the system upgrade process, and software development methods using the Waterfall method. After upgrading the Open Journal System (OJS) version of the ePublishing system Version 2.4.8 to Version 3.1.0.1, the management process became more flexible and efficient, and had a more attractive and customizable appearance.
\end{abstract}

Keywords - System Improvement, Open Journal System (OJS), Waterfall.

Vol. 9, No. 1, Januari 2019 


\section{PENDAHULUAN}

Jurnal merupakan sebuah karya tulis ilmiah yang disusun untuk memperluas ilmu pengetahuan dan penelitian atau melakukan penelitian untuk menemukan suatu temuan yang baru. Seorang mahasiswa harus membuat suatu karya ilmiah untuk kemudian dipublikasikan, karena merupakan salah satu syarat wajib kelulusan dan dalam jenjang karir peneliti dan dosen. Salah satu komponen penilaian kenaikan jabatan dosen adalah aspek penelitian dan publikasi ilmiah. Sesuai dengan surat edaran Kementerian Pendidikan dan Kebudayaan Direktorat Jenderal Pendidikan Tinggi Nomor : 152/E/T/2012, publikasi ilmiah menjadi syarat wajib bagi mahasiswa program sarjana untuk memperoleh kelulusan.

Saat ini pada perguruan tinggi di wilayah tangerang yang menjadi objek penelitian sudah menggunakan sistem pengelolaan dan publikasi jurnal ilmiah berbasis Open Journal Systems (OJS) Versi 2.4.8, namun pada versi ini masih terdapat kendala dalam proses pengelolaan jurnal diantaranya alur proses submission sampai dengan publish harus terurut, kemudian Open Journal System (OJS) Versi 2.4.8 juga belum mempunyai fitur yang lengkap dalam kustomisasi (customization), seperti tidak bisa Customize tampilan dengan mudah, penambahan dan pengurangan menu navigasi yang harus dilakukan secara langsung pada kode program (hard code), Pembuatan Struktur Organisasi Jurnal lebih sulit karena masing - masing divisi bagian harus mempunyai akun terlebih dahulu kemudian baru bisa dicantumkan ke dalam Struktur Organisasi, dan lain sebagainya.

Tujuan dari penelitian ini yaitu melakukan pengembangan sistem publikasi karya ilmiah berbasis Open Journal System (OJS) Versi 2.4.8 ke Versi 3.1.0.1 untuk mendukung proses pengelolaan menjadi lebih efisien dan flexible serta untuk mengembangkan sebuah sistem agar memiliki tampilan yang lebih menarik dan mudah di kustomisasi menggunakan tema bootstrap 3 sehingga memudahkan manajer jurnal dalam mengatur tampilan dan memudahkan pengguna dalam mengakses sistem seperti melakukan penyerahan jurnal, melihat artikel yang telah diterbitkan dan lain sebagainya dengan tampilan yang user-friendly.

Penelitian yang dilakukan oleh Yosua P.W Simaremare (2013) membahas tentang Perancangan dan Pembuatan Aplikasi Manajemen Publikasi Ilmiah Berbasis Online pada Jurnal SISFO. Jurusan Sistem Informasi ITS sebagai instansi pendidikan yang berperan sebagai pengelola publikasi ilmiah memiliki ruang lingkup pengelolaan mencakup jurnal SISFO yang diterbitkan tahunan. Proses pengelolaan saat dilakukan penelitian ini belum berbasis aplikasi memungkinkan terjadinya ketidakjelasan cakupan pembagian kerja, sehingga pengelolaan tidak berjalan efisien. Publikasi yang dilakukan saat ini masih melalui media cetak, sehingga belum dapat diakses secara mudah. Berbagai macam permasalahan yang ditemukan dalam pengelolaan jurnal ilmiah saat ini di Jurusan Sistem Informasi menjadi pokok dari dibutuhkannya aplikasi manajemen publikasi ilmiah berbasis online yang mampu mengelola kegiatan publikasi ilmiah untuk menciptakan pengelolaan dan publikasi yang lebih baik dan meningkatkan kemudahan akses. Metode perancangan aplikasi dalam penelitian ini dibangun dengan metode Unified Software Development Process dan perancangan aplikasi menggunakan Unified Modeling Language (UML). Mekanisme pengerjaan penelitian ini dibuat secara iteratif dari proses pembuatan Spesifikasi Kebutuhan Perangkat Lunak (SKPL), kemudian dilanjutkan dengan pembuatan Desain Perancangan Perangkat Lunak (DPPL), kemudian diikuti dengan pembuatan aplikasi dan ditutup dengan pengujian. Proses ini dilakukan terus menerus sesuai dengan jangka waktu perencanaan. Hasil dari penelitian ini adalah dokumen perancangan dan aplikasi manajemen publikasi ilmiah. Penerapan aplikasi manajemen publikasi ilmiah ini mampu meningkatkan kualitas dari proses pengelolaan jurnal ilmiah di Jurusan Sistem Informasi menjadi lebih sistematis dan terorganisir untuk mencapai efisiensi dan meningkatkan publikasi menjadi global.

Penelitian yang dilakukan oleh Micah Altman (2015) membahas tentang Perpustakaan semakin memiliki kesempatan untuk terlibat dengan bidang penerbitan akses terbuka. Penelitian ini menyediakan kerangka kerja dan alat operasional untuk mengintegrasikan penerbitan jurnal, data penerbitan, dan pelestarian data dengan akses terbuka. Dengan pendanaan dari Alfred P. 
Sloan Foundation, Proyek Dataverse (King 2007; Crosas, 2011, 2013) dari Universitas Harvard berkolaborasi dengan Public Knowledge Project (PKP) (MacGregor, Stranack \& Willinsky, 2014) dari Simon Fraser University dan Stanford University pada proyek open source untuk mengaktifkan jurnal dengan akses terbuka untuk mengelola pengajuan artikel, peninjauan, dan publikasi data terkait dengan artikel yang diterbitkan. Hasilnya adalah pengembangan perangkat lunak Open Journal Systems (OJS) PKP (Willinsky, 2005) dapat dengan mudah di instal dan digunakan untuk mengadopsi replikasi data, kutipan, pengarsipan dan kebijakan publikasi yang tepat. OJS sekarang mendukung alur kerja publikasi data yang lengkap dan dikirimkan sebagai bagian dari distribusi OJS standar dan secara otomatis serta terintegrasi dengan Dataverse untuk akses jangka panjang ke data penelitian yang terkait dengan artikel yang dipublikasikan. Proyek ini menghasilkan dua output utama: yaitu sebuah plugin untuk OJS yang mendukung pengajuan data, kutipan, tinjauan, dan alur kerja publikasi, dan ekstensi ke Dataverse yang menyediakan API standar. Hal ini telah diintegrasikan ke dalam pengembangan dan pemeliharaan proses dari paket open source masing-masing. Selain itu, ekstensi ini digunakan untuk mendukung interoperabilitas dengan sistem lain seperti Pusat Ilmu Pengetahuan Terbuka Open Science Framework (OSF) dan Archivematica dimulai pada musim panas 2015.

Penelitian yang dilakukan oleh Noer Fajrin (2016) membahas tentang Instalasi dan Implementasi Open Journal System di Local Area Network Laboratorium Telematika STEIITB. Open Journal System (OJS) merupakan salah satu solusi terbaik dalam penerbitan jurnal secara online, sehingga memiliki jurnal elektronik menjadi sebuah kebutuhan mutlak bagi perguruan tinggi. Instalasi dan Implementasi Open Journal System di Local Area Network STEI-ITB, dilakukan pada komputer yang menggunakan sistem operasi Linux Ubuntu, dan menggunakan XAMPP untuk membuat server yang mampu berdiri sendiri dalam komputer desktop. Instalasi dan implementasi dilakukan secara lokal dalam jaringan LAN di Lab. Telematika STEI-ITB. Dalam penelitian ini juga dipaparkan mengenai cara penggunaan OJS dan cara mengimplementasikan penerbitan sebuah jurnal di OJS. Mulai dari pembuatan pengguna atau user, serta penjelasan mengenai peran setiap pengguna di OJS, proses editorial dalam OJS, sampai penerbitan sebuah jurnal di OJS. Tujuan dari penelitian Instalasi dan Implementasi OJS di LAN Lab. Telematika STEI ITB ini adalah memahami cara Instalasi OJS, serta mengetahui cara Implementasi OJS yang berupa simulasi penerbitan sebuah jurnal di OJS, yang mampu diakses secara bebas oleh seluruh pengguna yang terkoneksi dengan LAN Lab. Telematika STEI-ITB.

Penelitian yang dilakukan oleh Nurlaila Suci Rahayu Rais (2018) membahas tentang Instalasi Open Journal System (OJS) Versi 3 Sebagai Pendukung Kegiatan Pengelolaan dan Publikasi Jurnal Ilmiah. Open Journal System (OJS) adalah perangkat lunak (software) open source yang digunakan untuk mengelola dan mempublikasikan jurnal ilmiah secara online. OJS dikembangkan oleh Public Knowledge Project sejak tahun 2001. Fitur yang terdapat pada OJS mulai dari sebuah artikel dikirim oleh penulis (Author), proses review oleh Reviewer, dan lain sebagainya hingga artikel tersebut diterima untuk diterbitkan dalam sebuah jurnal. OJS versi terbaru yaitu OJS versi 3 dirilis pada tahun 2016. Tujuan dari penelitian ini adalah untuk memahami cara instalasi OJS versi 3 serta untuk mengetahui kelebihan OJS versi 3 yang dapat mendukung kegiatan pengolahan dan publikasi jurnal ilmiah elektronik (e-journal), metode yang digunakan oleh penulis menggunakan metode analisis kebutuhan diantaranya menganalisis kebutuhan yang dibutuhkan dalam dalam proses instalasi Open Journal System (OJS) versi 3 dan Flowchart Instalasi OJS untuk menggambarkan tahap-tahap yang dilakukan dalam proses instalasi OJS versi 3. dengan dilakukannya instalasi Open Journal System (OJS) Versi 3 diharapkan dapat mendukung dan memberi kemudahan dalam kegiatan pengelolaan dan publikasi jurnal ilmiah secara online.

Penelitian yang dilakukan oleh Indri Handayani (2018) membahas tentang Pemanfaatan Sistem iJC Berbasis OJS Sebagai Media E-Journal Pada STISIP YUPPENTEK. Di dalam pengelolaan karya ilmiah di STISIP YUPPENTEK pada saat dilakukan penelitian ini masih manual sehingga memiliki permasalahan-permasalahan seperti penerbitan jurnal yang begitu susah dan data terpisah-pisah karena membutuhkan waktu cukup lama dan biaya cukup besar.

Vol. 9, No. 1, Januari 2019 
Artikel ilmiah pada STISIP YUPPENTEK belum memenuhi syarat ketentuan dikti perihal akreditasi jurnal yang mengharuskan jurnal dikelola dengan cara online dalam pengelolaan yang dilakukan lebih dengan mudah dan cepat. Setelah peneliti menganalisa permasalahan dengan menggunakan suatu metode pengumpulan data berupa observasi, wawancara dan studi pustaka serta menggunakan UML (Unified Modeling Language). Untuk mengatasi permasalahan tersebut peneliti memberikan usulan sistem yang memudahkan pengguna sehingga proses pengelolaan jurnal dapat lebih memudahkan pengguna.

Penelitian yang dilakukan oleh Untung Rahardja (2018) membahas tentang Penerapan Viewboard Technomedia Journal menggunakan sistem iLearning Journal Center pada Perguruan Tinggi. TMJ merupakan sebuah sistem pelayanan penulisan karya ilmiah atau jurnal dari hal memberitahukan informasi pembukaan jurnal, template jurnal dan submit jurnal dengan tujuan, memberitahukan kepada seluruh mahasiswa sehingga tidak mengalami kekurangan dalam informasi mengenai jurnal. Tujuan dari Viewboard TMJ adalah sebagai tempat pelayanan informasi dari data-data yang sudah ada dan terkait dengan penulisan karya ilmiah atau jurnal sehingga nanti nya akan menampilkan informasi yang valid juga dapat mudah untuk dipantau dengan menggunakan berbasis komputer, hal ini memudahkan admin untuk mengelola data yang terdapat pada TMJ menjadi sebuah Viewboard. Viewboard ini berbasis web karena Viewboard yang diterapkan untuk menampilkan informasi menggunakan website. Pada penelitian ini penulis menggunakan metode implementasi. implementasi atau pengujian adalah tahapan dimana software yang telah selesai dikembangkan dilakukan pengujian dengan metode blackbox agar semua komponen sistem apakah sesuai dengan analisis kebutuhan pada awal perancangan, kemudian menggunakan metode pengumpulan data mulai dari observasi mengenai OJS, wawancara kepada pihak-pihak terkait, serta studi pustaka yang dilakukan oleh penulis.

\section{METODE PENELITIAN}

Di dalam mengembangkan sebuah sistem pengelolaan dan publikasi $e$-journal berbasis Open Journal System (OJS) Versi 2.4.8 ke Versi 3.1.0.1, pada penelitian ini metode penelitian yang digunakan meliputi metode analisis permasalahan, metode analisis kebutuhan yang diperlukan dalam proses mengembangkan sistem, dan metode untuk pengembangan perangkat lunak menggunakan metode Waterfall.

Metode pertama peneliti melakukan analisis permasalahan yang ada dengan cara menentukan dan merumuskan permasalahan yang dihadapi pada saat proses pengelolaan dan publikasi karya ilmiah masih menggunakan Open Journal System (OJS) Versi 2.4.8. Adapun rumusan permasalahannya yaitu pertama, pada saat proses pengelolaan jurnal masih menggunakan Open Journal System (OJS) Versi 2.4.8, pengelolaan tidak berjalan secara efisien karena alur proses pengelolaan jurnal lebih kaku dan harus terurut setiap langkahnya, proses pengaturan edisi terbitan dan arsip jurnal pada Open Journal System (OJS) Versi 2.4.8 harus input kembali data-data jurnal yang akan diterbitkan seperti judul, abstrak, kata kunci dan lain sebagainya. Kedua, manajer jurnal kesulitan untuk mengatur peran pengguna jurnal, mengatur kebijakan dan prosedur persyaratan Submit jurnal. Ketiga, kurangnya minat penulis dalam membuat karya ilmiah dengan tampilan sistem yang kurang menarik karena tampilan sistem cenderung kaku.

Metode kedua metode penelitian yang digunakan setelah analisis permasalahan adalah analisis kebutuhan. pada tahap ini hal yang dilakukan yaitu mengidentifikasikan seluruh kebutuhan yang diperlukan untuk mengembangkan sebuah sistem pengelolaan jurnal dan publikasi karya ilmiah berbasis online sehingga dapat meminimalisir hambatan-hambatan yang akan terjadi. Adapun kebutuhan yang diperlukan pada penelitian ini yaitu pertama, Software Open Journal System (OJS) Versi 3.1.0.1. Kedua, tema bootstrap 3. Salah satu kelebihan $e$ Publishing systems Open Journal System (OJS) Versi 3.1.0.1 adalah dapat melakukan kustomisasi tampilan OJS sesuai yang dibutuhkan dengan menggunakan tema agar tampilan lebih menarik. Ketiga, Web Hosting. Salah satu kebutuhan dalam mengembangkan sistem OJS 
adalah Web Hosting karena file-file website sistem berbasis online akan tersimpan di Server Web Hosting.

Metode ketiga, metode pengembangan sistem. setelah melakukan identifikasi segala kebutuhan yang diperlukan untuk proses pengembangan sebuah sistem pengelolaan jurnal dan publikasi karya ilmiah pada tahap analisis kebutuhan, maka pada tahap ini akan membahas proses pengembangan perangkat lunak dengan menggunakan metode waterfall karena metode tersebut sesuai dengan pengembangan sistem pada penelitian ini. Dalam metode waterfall ada beberapa tahapan yaitu analisis kebutuhan sistem (System Requirements Analysis), desain sistem (System design), Implementasi dan Pengujian unit (Implementation and Unit testing), pengujian sistem (System Testing), Operation and Maintenance.

\section{HASIL DAN PEMBAHASAN}

\subsection{Analisis permasalahan}

Melakukan analisis permasalahan yang ada dengan cara menentukan dan merumuskan permasalahan yang dihadapi pada saat proses pengelolaan dan publikasi karya ilmiah masih menggunakan Open Journal System (OJS) Versi 2.4.8. Adapun rumusan permasalahan yang dihadapi pada penelitian ini adalah sebagai berikut:

1. Pada saat proses pengelolaan jurnal masih menggunakan Open Journal System (OJS) Versi 2.4.8, pengelolaan tidak berjalan secara efisien karena :

a. Dengan alur proses pengelolaan jurnal Open Journal System (OJS) yang sangat panjang, pada OJS Versi 2.4.8 harus terurut setiap langkahnya sehingga bersifat lebih kaku dan tidak flexible.

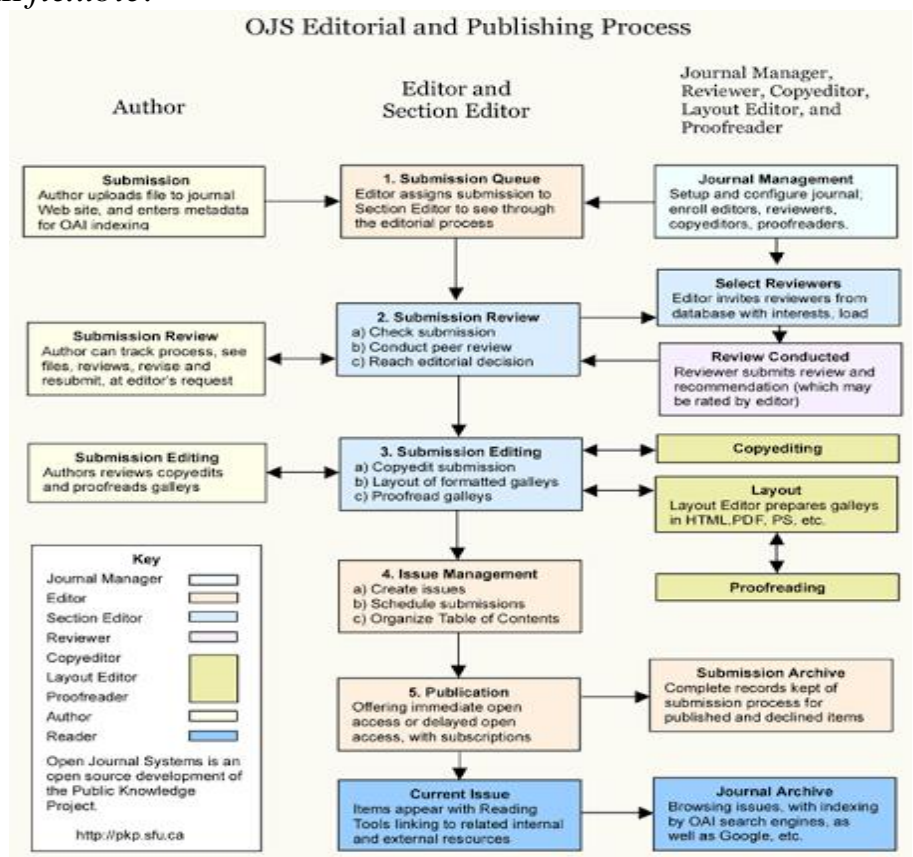

Gambar 1. Alur proses penerbitan jurnal OJS

b. Proses pengaturan edisi terbitan dan arsip jurnal pada Open Journal System (OJS) Versi 2.4.8 data-data jurnal tidak tersinkronisasi dan harus input kembali data-data jurnal yang akan diterbitkan seperti judul, abstrak, kata kunci dan lain sebagainya.

2. Manajer jurnal kesulitan untuk mengatur peran pengguna jurnal, mengatur kebijakan dan prosedur persyaratan Submit jurnal.

3. Kurangnya minat penulis dalam membuat karya ilmiah dengan tampilan yang kurang menarik karena tampilan sistem cenderung kaku. 


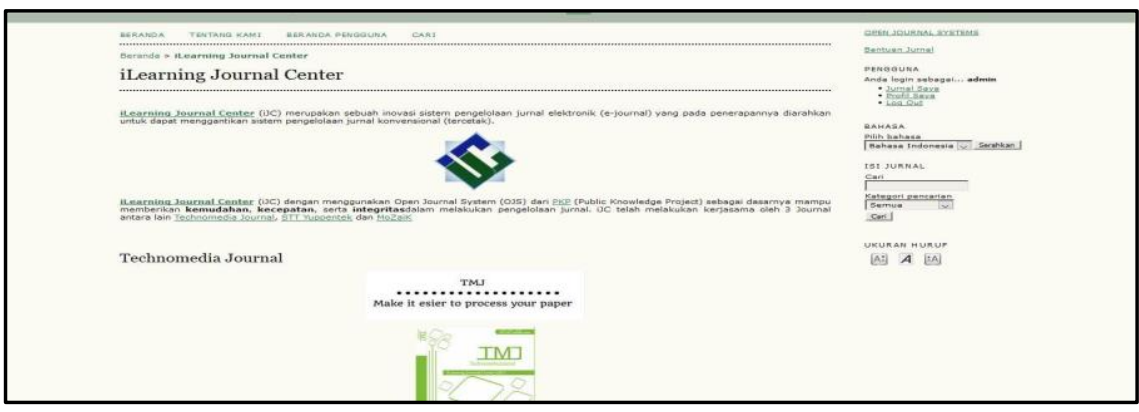

Gambar 2. Tampilan OJS Versi 2.4.8

\subsection{Analisis Kebutuhan}

Analisis kebutuhan yang dilakukan yaitu mengidentifikasikan seluruh kebutuhan yang diperlukan untuk mengembangkan sebuah sistem pengelolaan jurnal dan publikasi karya ilmiah berbasis online sehingga dapat meminimalisir hambatan-hambatan yang akan terjadi. Adapun kebutuhan yang diperlukan pada penelitian ini yaitu:

1. Software Open Journal System (OJS) Versi 3.1.0.1.

Untuk mengembangkan sistem pengelolaan jurnal dan publikasi karya ilmiah, software Open Journal System (OJS) Versi 3.1.0.1 adalah kebutuhan utama, karena Open Journal System (OJS) Versi 3.1.0.1 memiliki kelebihan diantaranya:

a. Fiture pengelolaan artikel Open Journal System (OJS) Versi 3.1.0.1 sangat lengkap.

b. Proses pengembangan dan pemeliharaan serta pengembangan OJS Versi 3.1.0.1 lebih mudah dan cepat.

c. Tampilan OJS Versi 3.1.0.1 dapat di-customize menggunakan tema.

d. Pada penelitian ini versi OJS yang digunakan adalah versi 3.1.0.1 yang dapat di unduh secara mudah melalui alamat website resmi Public Knowledge Project (PKP) berikut http://pkp.sfu.ca/ojs_download.

2. Tema Bootstrap 3.

Salah satu kelebihan e-Publishing systems Open Journal System (OJS) Versi 3.1.0.1 adalah dapat melakukan kustomisasi tampilan OJS sesuai yang dibutuhkan dengan menggunakan tema agar tampilan lebih menarik. Pada penelitian ini akan mengembangkan sebuah sistem pengelolaan dan publikasi karya ilmiah berbasis online dengan menggunakan tema bootstrap 3. Pada halaman website resmi Public Knowledge Project (PKP) telah memberikan informasi bahwa PKP telah menyediakan tema bootstrap 3 dan memberikan petunjuk pemasangan serta pengembang dapat melihat demonstrasi tema yang telah diterapkan pada OJS 3.

3. Web Hosting.

Salah satu kebutuhan dalam mengembangkan sistem OJS adalah Web Hosting karena file-file website sistem berbasis online akan tersimpan di Server Web Hosting. Hal yang harus diperhatikan adalah:

a. Versi PHP harus menggunakan PHP $>=5.6 .0$

b. MySQL $>=4.1$ atau PostgreSQL $>=9.1 .5$

c. Apache $>=1.3 .2 \mathrm{x}$ atau $>=2.0 .4 \mathrm{x}$ atau Microsoft IIS 6

d. Serta sistem operasi yang mendukung OJS yaitu Linux, BSD, Solaris, Mac OS X, dan Windows.

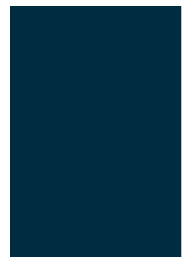

upgrade

If you are upgrading an existing installation of ojs, click here to proceeed.

Recommended system requirements

- PHP >- 5.6.0; you are currently using PHP 5.6.24

- Mysel $>=4.1$ or Postgresol $>9.15$

Gambar 3. Persyaratan sistem OJS Versi 3.1.0.1

4. Web Browser 
Pada saat mengembangkan sistem OJS memerlukan Web Browser karena proses pengembangan OJS dilakukan melalui Web Browser dan proses pengembangan dilakukan di Web Hosting seperti proses instalasi OJS. Contoh web browser yaitu Internet Explorer, Chrome, FireFox, Opera, Safari, Lynx, dll. Web browser yang digunakan pada penelitian ini adalah FireFox.

\subsection{Pengembangan Sistem}

Setelah melakukan identifikasi segala kebutuhan yang diperlukan untuk proses pengembangan sebuah sistem pengelolaan jurnal dan publikasi karya ilmiah pada tahap analisis kebutuhan, maka pada tahap ini akan membahas proses pengembangan perangkat lunak dengan menggunakan metode Waterfall merupakan sebuah metode dalam pengembangan sistem yang dilakukan untuk membuat pembaruan sistem yang berjalan. Berikut ini adalah tahap-tahap pengembangan Open Journal System (OJS) menggunakan metode Waterfall:

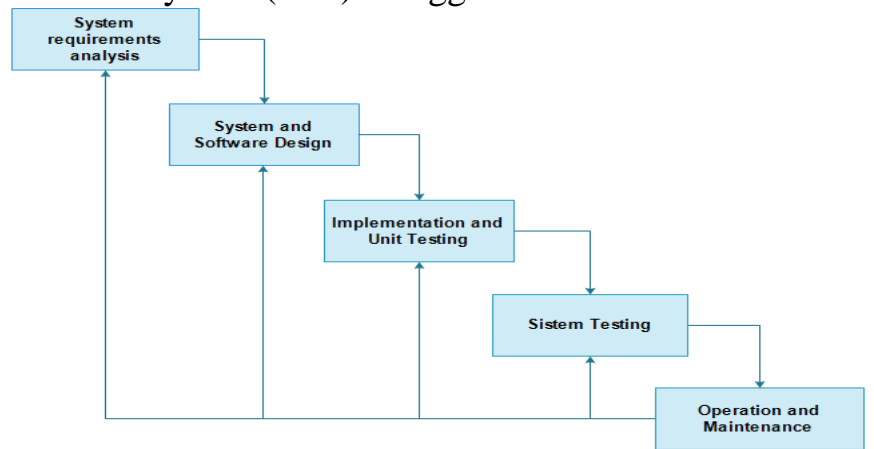

Gambar 4. Metode Waterfall

a. Analisis Kebutuhan Sistem (System Requirements Analysis)

Tahap ini dilakukan untuk Mengidentifikasi kebutuhan sistem. yang menjadi kebutuhan sistem pada metode Waterfall ini adalah informasi mengenai proses - proses yang belum optimal yang terdapat pada Open Journal System (OJS) Versi 2.4.8 diantaranya proses submission, dengan alur proses Submit OJS yang cukup panjang proses submission pada OJS 2 sampai dengan publish harus terurut tidak flexible workflow. Pada saat proses seleksi penerimaan jurnal untuk diterbitkan, tentu editor jurnal harus memeriksa terlebih dahulu artikel-artikel yang telah diserahkan oleh penulis dan artikel - artikel tersebut diperiksa berdasarkan ketentuan yang telah ditetapkan oleh lembaga penelitian yang terdapat di berbagai Universitas atau Perguruan Tinggi yang dikenal sebagai Lembaga Penelitian dan Lembaga Pengabdian kepada Masyarakat (LPPM) setelah lolos proses seleksi penerimaan artikel, maka artikel tersebut akan diproses lebih lanjut oleh masing - masing peran pengelola jurnal secara terurut hingga artikel tersebut dinyatakan layak untuk diterbitkan, ketika terdapat artikel yang diserahkan oleh penulis dan artikel tersebut sudah sesuai dengan ketentuan-ketentuan yang sudah ditetapkan oleh LPPM dan hanya perlu dirapikan format penulisan saja, tetapi harus melewati proses review dan proses - proses lainnya tidak bisa langsung dilanjutkan ke proses production sehingga tidak efektif. Managing, untuk mengatur peran pengguna harus masuk ke menu "user home" lalu kemudian memilih role yang diinginkan kemudian kembali lagi ke menu "user home" tidak flexible roles. Kemudian untuk pengaturan tampilan (look), untuk melakukan kustomisasi tampilan tidak bisa dengan mudah, penambahan dan pengurangan menu navigasi yang harus dilakukan secara langsung pada kode program (hardcode) sehingga memerlukan waktu untuk melakukan pengkodingan hanya untuk menambahkan menu navigasi.

b. Desain Sistem (System Design)

Desain atau perancangan sistem merupakan proses merancang dan menggambarkan secara rinci bagaimana sistem akan dibuat sehingga menghasilkan sistem perangkat lunak sesuai dengan perancangan yang telah dilakukan. Di dalam penelitian ini melakukan perancangan untuk pengembangan sistem pengelolaan e-journal berbasis OJS Versi $2.4 .8 \mathrm{ke}$ Versi 3.1.0.1 dari kedua sistem tersebut tentu memiliki perbedaan dari segi tampilan sistem, alur proses sistem maupun yang lainnya. maka pada tahap pertama melakukan proses 
merancang tampilan sistem dengan membuat prototype system untuk menggambarkan tampilan sistem yang akan dikembangkan. Pada penelitian ini akan membuat sebuah sistem yang userfriendly diantaranya akan membuat menu navigasi yang dibutuhkan pengguna. Menu navigasi dan sidebar halaman beranda OJS untuk terbagi menjadi 2 (dua) yaitu pada saat sebelum melakukan login dan sesudah login. Menu navigasi sebelum login seperti login, register, tentang kami, beranda website dan menu sesudah login seperti beranda website, tentang kami dan beranda pengguna. Kemudian menu sidebar sebelum login terdapat form login yang berisikan username dan password pengguna, menu untuk pilihan bahasa sistem yaitu bahasa indonesia dan bahasa inggris, dan menu untuk pencarian content yang terdapat pada sistem dan sidebar sesudah login terdapat nama pengguna yang melakukan login, dan dibawahnya terdapat menu yang sama dengan sebelum login yaitu menu untuk pilihan bahasa sistem yaitu bahasa indonesia dan bahasa inggris, dan menu untuk pencarian content yang terdapat pada sistem. melakukan kustomisasi header website, di bagian header menggunakan logo website dan nama lembaga penerbitan jurnal dengan jelas kemudian kustomisasi footer, di bagian footer terdapat logo website lembaga penerbitan jurnal yang berisikan versi ojs, pengelola website dan statcounter.

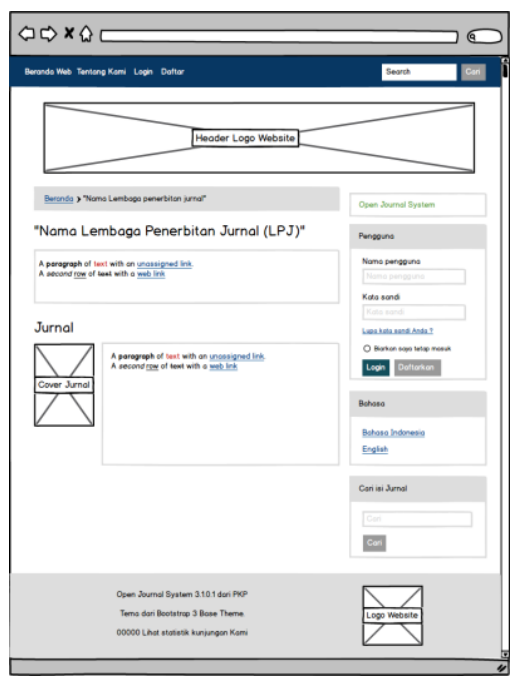

Gambar 5. Desain Halaman Beranda OJS Versi 3.1.0.1.

c. Implementasi dan Pengujian unit (Implementation and Unit Testing)

Melakukan implementasi sistem dengan melakukan proses pengembangan sesuai dengan hasil proses perancangan sistem, ke dalam sistem yang dikembangkan yang akan dijelaskan setiap tahapannya berikut ini :

1) Unduh Software OJS Versi 3.1.0.1

Proses pertama yaitu unduh terlebih dahulu software OJS Versi 3.1.0.1 yang bisa diunduh melalui situs resmi dari Public Knowledge Project (PKP).

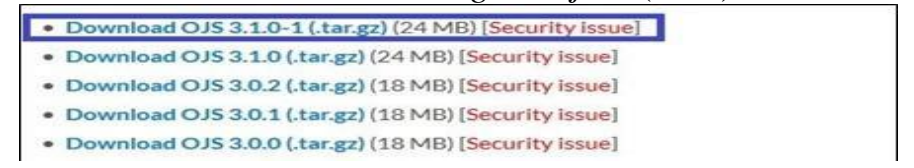

Gambar 6. Unduh File OJS Vrersi 3.1.0.1

2) Unggah Software instalasi OJS ke Web Hosting

Untuk dapat melakukan instalasi OJS secara online, unggah software OJS ke Web

Hosting. Cara mengunggahnya dapat dilihat berikut ini :

a. Pertama Login terlebih dahulu ke Web Hosting.

b. Pilih file manager, kemudian klik menu Upload yang terdapat di bagian atas file manager.

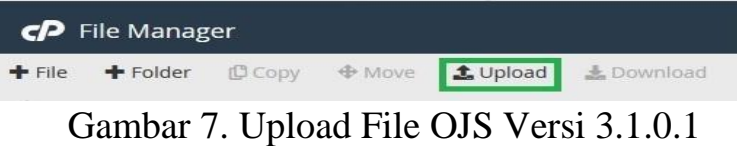


c. Setelah itu akan tampil menu Upload

d. Untuk mulai meng-unggah klik Select File dan tunggu hingga 100 persen.

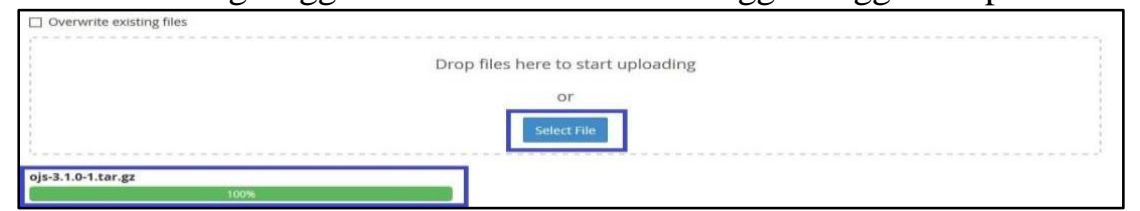

Gambar 8. Proses Upload File OJS Versi 3.1.0.1

e. Setelah selesai mengunggah File Software OJS 3, kemudian kembali ke File Manager.
雨 index.php
$2.9 \mathrm{~KB} \quad$ Jul 31, 2018, 5:53 PM
[형 ojs-3.1.0-1.tar.gz
管 README.mo
$22.9 \mathrm{MB} \quad$ Today, 10:49 PM
2.39 KB Jul 28, 2018, 8:40 AM

Gambar 9. Hasil Upload File OJS Versi 3.1.0.1

3) Ekstrak Software Instalasi OJS Versi 3.1.0.1

Melakukan ekstraksi software OJS 3 yang telah di-upload pada tahap sebelumnya.

Gambar 10. Hasil Ekstraksi File OJS Versi 3.1.0.1

4) Pindah dan Ganti File (Move and Replace)

Setelah proses ekstraksi file OJS Versi 3.1.0.1 selesai, selanjutnya pindahkan file - file yang terdapat didalam folder yang telah di ekstrak ke folder "public_html" kecuali folder untuk menyimpan file biasanya diberi nama "files" tetapi dalam penelitian ini diberi nama "ojsdata", folder "public", dan icon website "favicon.ico". dengan cara pilih semua file yang terdapat didalam folder ojs-3.1.0-1 kecuali folder -folder dan icon website yang telah disebutkan sebelumnya kemudian klik kanan dan pilih move kemudian muncul halaman untuk mengatur tempat tujuan file yang akan dipindahkan yaitu folder "public_html".

5) Buka halaman Website

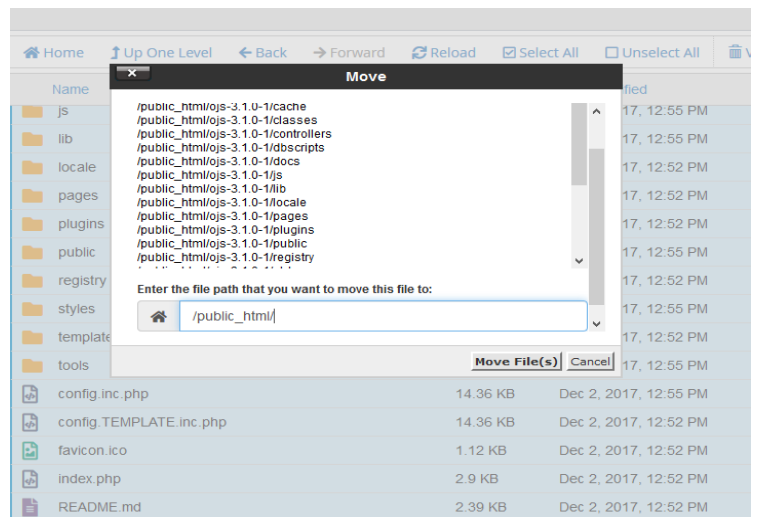

Gambar 11. Move and Replace.

Membuka halaman website melalui browser untuk memulai proses pengembangan OJS Versi 2.4.8 ke Versi 3.1.0.1 sebelum memulai proses upgrade hal yang harus dilakukan yaitu mengatur file "config.php" OJS3 Versi 3.1.0.1 untuk disesuaikan dengan file "config.php" OJS Versi 2.4.8. Yang harus disesuaikan yaitu mengatur "General Settings" yaitu installed = Off, base_url = " http://ijc.ilearning.co/" atau URL OJS yang akan dikembangkan, kemudian mengatur "Database Settings" seperti driver = mysql, host $=$ localhost, username $=$ root, password $=$ user123, name $=$ ojs3, kemudian mengatur "File Settings" files_dir = "C:|xamppไhtdocslojss", serta mengatur OAI Settings repository_id = "ojs3.ijc.ilearning.me" atau repository_id $=$ "ojs3.(URL website OJS yang akan dikembangkan)". Jika pada proses instalasi OJS melengkapi form instalasi yang terdapat pada halaman awal, maka pada proses pengembangan OJS dibagian "Upgrade" klik "Click here" untuk menuju halaman proses upgrade. Setelah itu akan muncul halaman untuk memulai proses upgrade klik tombol 
"Upgrade Open Journal System" kemudian proses upgrade akan dimulai dan tunggu beberapa saat sampai proses upgrade selesai dan muncul halaman seperti gambar dibawah ini.
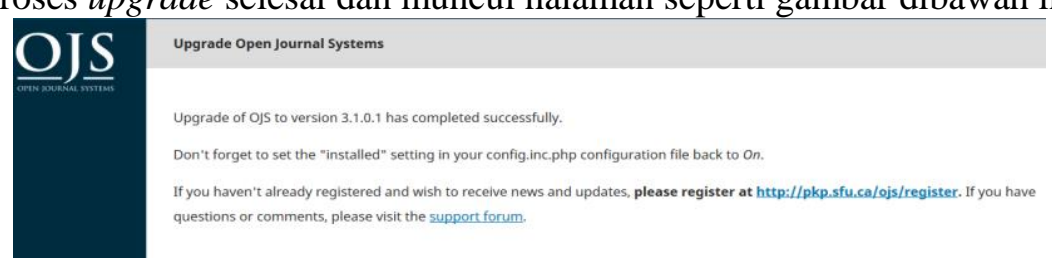

Gambar 12. Proses Upgrade Selesai.

Setelah proses upgrade selesai, ikuti instruksi yang terdapat pada halaman diatas untuk mengatur kembali "general settings" yang sebelum upgrade telah diatur installed $=$ Off sekarang diatur menjadi installed $=$ On supaya bisa menuju halaman default OJS3 Versi 3.1.0.1.

6) Proses Instalasi Tema :

a. Tema Bootstrap 3.

Unduh tema bootstrap 3 yang telah disediakan oleh Publik Knowledge Project (PKP) yang bisa diunduh di situs resmi PKP.

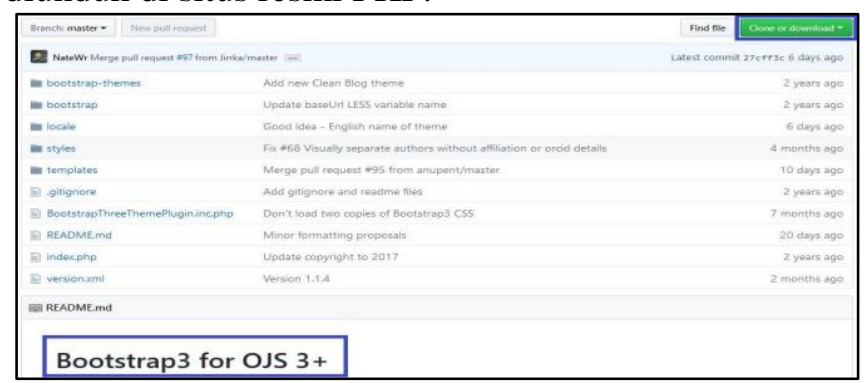

Gambar 13. Halaman Unduh Tema Bootstrap

b. Unggah File Tema Bootstrap 3.

Login ke dalam web hosting dan unggah tema yang telah diunduh, ke dalam folder direktori “/public_html/plugins/themes/".

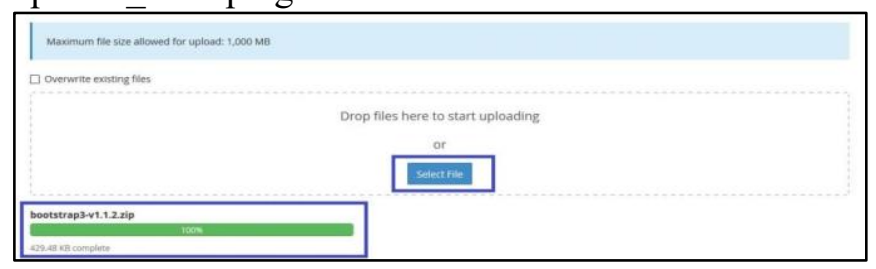

c. Ekstrak File Tema.

Gambar 14. Halaman Unggah Tema Bootstrap.

Ekstrak File tema bootstrap 3 yang telah diunggah pada tahap sebelumnya ke dalam direktori “/public_html/plugins/themes/".

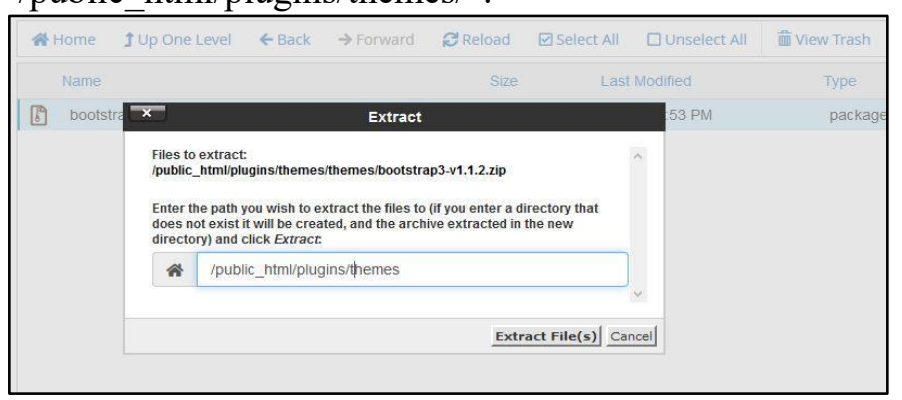

Gambar 15. Proses Ekstrak File Tema

d. Ganti nama Folder.

Sebelum memulai proses mengaktifkan tema, Ganti nama folder tema yang sudah di ekstrak sebelumnya "bootstrap3-v1.1.2" menjadi "bootstrap3".

e. Mengaktifkan Tema. 
Setelah proses mengunduh dan mengunggah file tema bootstrap 3, maka selanjutnya proses mengaktifkan tema bootstrap 3 dengan cara :

1) Login terlebih dahulu sebagai Admin ke sistem OJS.

2) Masuk ke halaman Administrator.

3) Kemudian masuk ke pengaturan situs dengan cara pilih menu "Settings" kemudian pilih "Website" dan pilih tab "Plugin".

4) Kemudian scroll ke bagian paling bawah dan cari pengaturan untuk Plugin Tema yaitu Theme Plugins, pilih dan ceklis Bootstrap 3 Base Theme untuk mengaktifkan Tema Bootstrap 3.

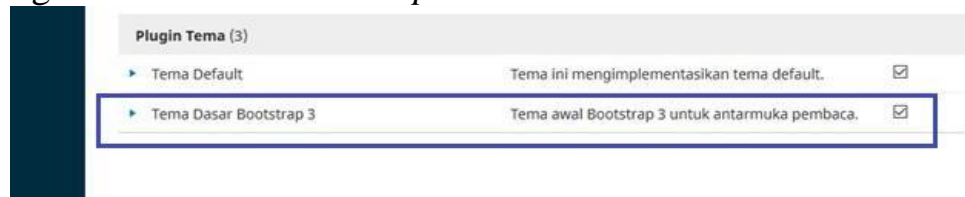

Gambar 16. Halaman Plugins

5) Memilih dan Menggunakan Tema.

Pada tahap ini adalah proses untuk memilih dan menggunakan tema bootstrap 3 dengan cara:

a. Scroll kembali kebagian atas, kemudian pilih tab Appearance.

b. Kemudian setelah masuk ke halaman Appearance, pada bagian Theme pilih Bootstrap 3 Base Theme. Pada penelitian ini menggunakan Tema Bootstrap 3 dengan tipe Flatly.

c. Setelah telah selesai memilih tipe tema, scroll ke bagian paling bawah halaman kemudian klik tombol Save.

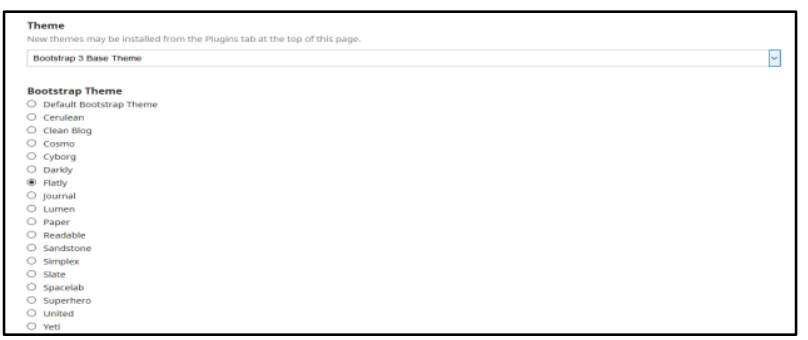

Gambar 17. Pilih Tema.

f. Refresh Halaman Website.

Buka kembali halaman website jurnal setelah itu akan terlihat bahwa tema default untuk sistem OJS telah diganti menjadi tema bootstrap 3 dengan tipe Flatly.

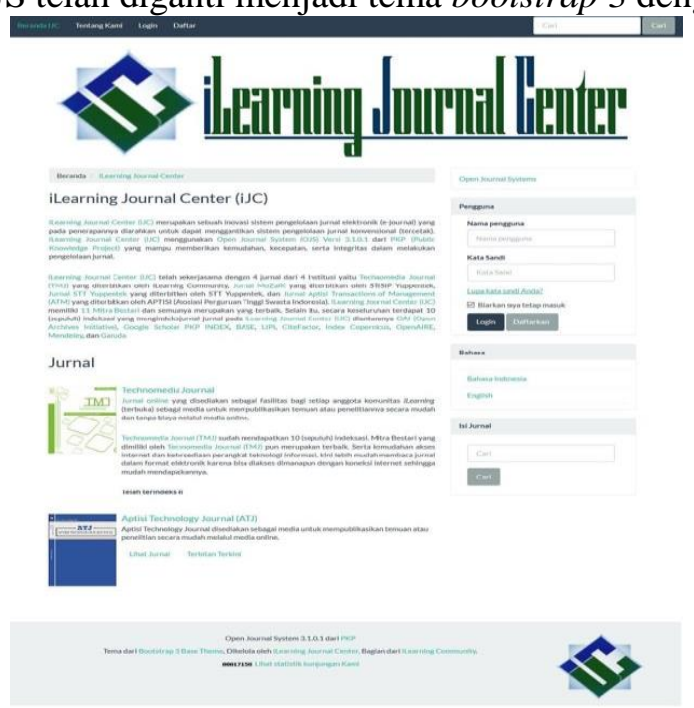

Gambar 18. Tema Bootstrap 3 
Dengan menggunakan tema bootstrap 3 halaman website jurnal akan terlihat lebih rapi sehingga menarik minat Author ataupun Reader dan lain sebagainya untuk menerbitkan karya ilmiahnya atau untuk membaca karya ilmiah yang telah diterbitkan.

d. Pengujian Sistem (System Testing)

Melakukan pengujian sistem dengan cara melakukan pengujian terhadap sistem secara menyeluruh dari perangkat lunak sistem, fungsi sistem, dan mencari segala kemungkinan kesalahan dari proses awal hingga akhir sehingga alur proses sistem dapat teruji dan dapat meminimalisir kemungkinan kesalahan yang akan terjadi.

\section{e. Operation and Maintenance}

Setelah sistem diuji melalui proses pengujian sistem pada tahap sebelumnya, maka dilakukan pemeliharaan sistem dengan cara diadakan pemeriksaan fungsi sistem secara rutin untuk memastikan sistem beroperasi dengan baik.

\section{KESIMPULAN}

Berdasarkan pembahasan dari penelitian diatas dapat disimpulkan bahwa Public Knowledge Project (PKP) terus menyempurnakan sistem pengelolaan jurnal Open Journal System (OJS) agar dapat memudahkan pengguna khususnya untuk pengelola jurnal dan penulis untuk menerbitkan artikelnya secara online sehingga mendorong lembaga penerbitan jurnal untuk mengikuti dan mengembangkan OJS ke versi berikutnya agar dapat meningkatkan efisiensi dalam mengelola jurnal. Seperti dalam penelitian ini yang mengembangkan Open Journal System (OJS) Versi 2.4.8 ke Versi 3.1.0.1 karena pada saat ini versi tersebut terdapat fitur yang lengkap untuk melakukan pengelolaan jurnal kemudian di dalam OJS versi 3 memiliki tampilan yang rapi dan jelas serta dapat diatur sesuai kebutuhan dan pada OJS versi 3 ini dapat dikustomisasi tampilan atau menu-menu desain lembaga penerbitan jurnal itu sendiri. Dengan dilakukannya penelitian pengembangan sistem OJS ini diharapkan dapat memudahkan pengelola jurnal dalam melakukan proses mengelola jurnal hingga terbit dan juga dapat menarik minat penulis untuk melakukan submit artikel dengan kemudahan - kemudahan yang terdapat didalam sistem yang sudah dikembangkan pada penelitian ini.

\section{SARAN}

Berdasarkan dari pembahasan yang penulis telah diuraikan sebelumnya, Maka menyimpulkan saran diantaranya, seiring dengan cepatnya perkembangan Open Journal System (OJS) yang dirilis oleh Public Knowledge Project (PKP) dapat menimbulkan kebimbangan dalam memilih versi sistem OJS yang akan digunakan dalam proses pengembangan dari versi sebelumnya ke versi berikutnya, maka perlu dilakukan uji coba pengembangan dari beberapa versi berikutnya sehingga nantinya yang dipilih adalah sistem yang memang bisa digunakan untuk proses pengembangan OJS dari versi sebelumnya, sebelum dilakukan proses pengembangan tersebut.

\section{UCAPAN TERIMA KASIH}

Ucapan terima kasih penulis kepada Perguruan Tinggi Raharja yang telah memberi dukungan, fasilitas, serta finansial sehingga penulis dapat menyelesaikan penelitian ini dengan baik.

\section{DAFTAR PUSTAKA}

[1] Simaremare, Y., Pribadi, A., \& Wibowo, R. P. (2013). Perancangan dan Pembuatan Aplikasi Manajemen Publikasi Ilmiah Berbasis Online pada Jurnal SISFO. Jurnal Teknik ITS (POMITS), 2(3), 471-475. 
[2] Altman, M., Castro, E., Crosas, M., Durbin, P., Garnett, A., \& Whitney, J. (2015). Open journal systems and dataverse integration - helping journals to upgrade data publication for reusable research. Code4Lib J, 30.

[3] N. Fajrin, L. Kamelia, and T. Juhana, "Instalasi dan Implementasi Open Journal System di Local Area Network Laboratorium Telematika STEI-ITB", Prosiding - Seminar Nasional Teknik Elektro UIN Sunan Gunung Djati Bandung, pp. 18-29, Jan. 2018.

[4] Rahayu Rais, N. S., Supriati, R., \& Danti, S. I. (1). Instalasi Open Journal System (OJS) Versi 3 Sebagai Pendukung Kegiatan Pengelolaan dan Publikasi Jurnal Ilmiah. $\begin{array}{lll}\text { Technomedia } & \text { Journal, }\end{array}$ https://doi.org/https://doi.org/10.5281/zenodo.1325983

[5] Handayani, I., Aini, Q., \& Sari, N. (2018). Pemanfaatan Sistem iJC Berbasis OJS Sebagai Media E-Journal Pada STISIP YUPPENTEK. Technomedia Journal, 2(2), 94-106. https://doi.org/https://doi.org/10.5281/zenodo.1325987

[6] Rahardja, U., Handayani, I., \& Wijaya, R. (2018). Penerapan Viewboard Technomedia Journal menggunakan sistem iLearning Journal Center pada Perguruan Tinggi. $\begin{array}{llll}\text { Technomedia } & \text { Journal, }\end{array}$ https://doi.org/https://doi.org/10.5281/zenodo.1325985 